\title{
Simple Chooser Option Evaluation
}

\author{
Minghan $\mathrm{Gao}^{1, *, \dagger}$, Yifei $\mathrm{Yu}^{2, \dagger}$ \\ ${ }^{1}$ South Kent School, South Kent, 06785, South Kent, Connecticut, United States \\ ${ }^{2}$ Vanke Meisha Academy, 518000, Shenzhen China \\ *Corresponding author.Email: harry_gao02@163.com,yuyifei@stu.vma.edu.cn \\ ${ }^{\dagger}$ These authors contributed equally.
}

\begin{abstract}
Financial instruments traded in the markets and investors' situations in such markets are becoming more complex. The paper examines the main aspects of options, emphasizing the variety of exotic options and their place in financial markets and the risk management process. As the exact valuation of exotic options is quite difficult, the article deals with the theoretical and practical aspects of pricing of chooser options that suggest a broad range of usage and application in different market conditions. It gives traders a generic view of European style vs American Style Options and simulates the Simple Black-Scholes Model. It is introduced with the simple example of the pricing of 'European call options on a no-dividend stock, and the simulation results are compared with an analytical solution. The calculations made in this article showed the price of Apple Inc. (AAPL) at one-year maturity, and it is closely correlated with the chosen time and less correlated with its strike price. Finally, this paper introduces Chooser Options and provides a pricing spreadsheet. Chooser options give the investor the privilege of choosing whether the option is a put or a call at some predetermined date. Generally, the investor chooses the more valuable option.
\end{abstract}

Keywords: call option, put option, exotic option, strike price, Black-Scholes Model, straddle

\section{INTRODUCTION}

An option is a contract between a shareholder and an intended buyer that gives the buyer the right, but not the obligation, to buy or sell the underlying asset at an agreed price later. The agreed price in the contract is called the strike price; the date is referred to as the expiration date. If they are used correctly, Derivative securities can help investors increase their expected returns and minimize their risk exposure. For the first time exchange, listed options were traded in 1973. Since then, the volumes of their trade had risen sharply all over the world. This development was determined by the specific features that options include. Empirical research presented in Financial literature [1] Cuthbertson, Nitzsche illustrated that options could be used in many ways to create various investment opportunities.

Standard types of options are traded actively, but new types of options arise as investors try to create hedging for their investment portfolios. Over the last decade, the size of the market of exotic options in welldeveloped financial markets has expanded. A large variety of such complex instruments is available to investors. In theory, the call option writer has an obligation to sell the underlying asset if the holder of the call option decides to exercise his right to buy. A put option gives the holder the right to sell a specified quantity of the underlying stock at the strike price on or before the expiration date [2] Avellaneda, Laurence; Whaley. The put option writer has an obligation to buy the underlying asset at the strike price if the holder decides to exercise his right to sell. The style of an option refers to when that option is exercisable.

In this paper, we use the Black-Scholes model to describe the price of the underlying asset. The following assumptions were made to derive the Black-Scholes model: there are no riskless arbitrage opportunities; there are no transaction costs; there are no dividends during the life of an option; security trading is continuous; the risk-free rate of interest and the stock price volatility is constant.

This research aims to determine the price of Apple Inc. (AAPL)'s chooser option at the half and one-year maturity, which will be later discussed in the article. Comparing call and put options with approximately the same price, around 11.5-11.8 dollars per share. However, the chooser option has the advantage of 8 dollars higher 
than them. Logical analysis and synthesis of scientific literature, one thousand times of simulations were utilized to test the reliability of this research.

\section{FIRM DESCRIPTION}

Apple (ticker symbol: AAPL) is one of the world's leading consumer electronics and personal computer companies. The Cupertino, California-based company, was established in 1977 as Apple Computer Inc. It dropped the "Computer" from its name in early 2007. Apple's current place in the global marketplace is a far cry from its humble beginnings, with Steve Jobs, Steve Wozniak and Ronald Wayne selling hand-made personal computer kits in the late '70s. The company continued to focus on personal computers for the following decades. Still, that focus has shifted more to consumer electronics such as the iPhone, iPad, and iPod in recent years. However, Apple also sells a range of related software, services, and applications, with some of the most prominent non-electronics products being the iCloud, iOS, Mac OS and Apple TV. In addition, the company sells and delivers digital applications and software through its iTunes Store, App Store, iBookstore and Mac App Store. Apple has remained focused on developing its own hardware, software, operating systems, and services to provide its customers with the best user experience possible. A significant fraction of the company's efforts also goes toward marketing and advertising as it believes such efforts are essential to the development and sale of its products. The company - the principal executive offices of which are located at 1 Infinite Loop, Cupertino, California 95014 - has retail stores worldwide, with more than 300 locations as of 2012. Apple has five reportable operating segments: Americas, Europe, Japan, Asia-Pacific and Retail. The geographic-based segments do not include the results of the Retail segment. Despite Apple's market-leading position, the company still faces several risk factors, including changing global economic conditions, fluctuating consumer demand, worldwide competition and potential supply chain disruptions. Apple has about 35,000 employees worldwide and had worldwide annual sales of US $\$ 32.48$ billion in its fiscal year ending September 29, 2008.

\subsection{Financial Summary}

AAPL Nasdaq Insider Activity provides trading information of corporate insiders, such as officers, directors, and any beneficial owners of more than 10\% of a company's equity securities class. An insider trading activity happens when corporate insiders trade in stock in their own companies.

\subsubsection{Holding summary}

Table 1. Proportional analysis of AAPL main block shareholders

\begin{tabular}{|c|c|c|c|}
\hline \multicolumn{3}{|c|}{ Large Block Owners } & 4,993 \\
\hline \multicolumn{3}{|c|}{ Total Number of Shares Held } & 9.7Billions \\
\hline \multicolumn{4}{|c|}{$\begin{array}{c}\text { Table 2. Proportional analysis of AAPL main block } \\
\text { shareholders }\end{array}$} \\
\hline $\begin{array}{l}\text { Monthly } \\
\text { Rotation }\end{array}$ & $\begin{array}{l}\text { Number } \\
\text { of Shares }\end{array}$ & $\begin{array}{l}\text { Value of } \\
\text { Change } \\
(\mathrm{MM})\end{array}$ & $\begin{array}{l}\% \text { of shares } \\
\text { Outstanding }\end{array}$ \\
\hline $\begin{array}{l}\text { Buyers } \\
9 / 5 / 21\end{array}$ & $351,849,320$ & $\$ 48,056.68$ & $36.7 \%$ \\
\hline $\begin{array}{l}\text { Sellers } \\
9 / 5 / 21\end{array}$ & $678,487,893$ & $\$ 85,259.91$ & $27.3 \%$ \\
\hline
\end{tabular}

Table 3. AAPL Shareholder structure \& Categories

\begin{tabular}{ll}
\hline Institutions & 4,918 Holders \\
Mutual Funds & 5,784 Holders \\
Other Major Holders & 75 Holders \\
\hline
\end{tabular}

Apple has been dealt a major blow over its App Store rules and ongoing fight with other technology developers. A judge has forced the iPhone maker to stop banning other apps from offering other ways to pay for digital services, away from its own payment systems

\subsubsection{Firm Portfolio}

Table 4. AAPL's main latest financial Status [3] NASDAQ

\begin{tabular}{ll}
\hline Exchange & NASDAQ-GS \\
Sector & Technology \\
Computer Manufacturing \\
I Year Target & $\$ 166.00$ \\
Today's High/Low & $\$ 154.63 / \$ 153.09$ \\
Share Volume & $57,866,066$ \\
Average Volume & $77,216,224$ \\
Previous Close & $\$ 153.65$ \\
52 Week High/Low & $\$ 154.98 / \$ 103.10$ \\
\hline
\end{tabular}

Table 5. Common Size Firm Market Activity Via NASDAQ

\begin{tabular}{ll}
\hline Market Cap & $2,675,151,562,000$ \\
P/E Ratio & 30.2 \\
Forward P/E 1 Yr. & 27.49 \\
Earnings Per Share (EPS) & $\$ 5.11$ \\
Annualized Dividend & $\$ 0.88$ \\
Ex-Dividend Date & Aug 6, 2021 \\
\hline
\end{tabular}




\begin{tabular}{ll}
\hline Dividend Pay Date & Aug 12, 2021 \\
Current Yield & $0.58 \%$ \\
Beta & 1.2 \\
\hline
\end{tabular}

\subsubsection{Nearest dividend Summary}

A cash dividend payment of $\$ 0.22$ per share is scheduled to be paid on August 12, 2021. Shareholders who purchased AAPL prior to the ex-dividend date are eligible for the cash dividend payment. This represents an $-73.17 \%$ decrease from the prior dividend payment.

Nasdaq provides AAPL's real-time statistical data according to this table from Sep. 2nd, 2021. NLS Volume, Previous Close, Today's High \& Low, and the 52 weeks High \& Low. The intraday chart, the last five real-time quotes and sales data. Real-time stock quotes can be used to help inform investors when researching potential investment opportunities.

\subsection{Stock Price History}

Table 6. Statement of comprehensive annual income [4] Stock-Analysis-on.net

\begin{tabular}{ll}
\hline Beta (5Y Monthly) & 1.20 \\
52-Week Change 3 & $27.03 \%$ \\
S\&P500 52-Week Change 3 & $32.39 \%$ \\
52 Week High 3 & 154.98 \\
52 Week Low 3 & 103.10 \\
50-Day Moving Average 3 & 147.85 \\
& \\
200-Day Moving Average 3 & 133.74 \\
\hline
\end{tabular}

Analysis: According to the latest long-term forecast, Apple price will hit $\$ 200$ by the middle of 2022 and then $\$ 250$ by the end of 2023. Apple will rise to $\$ 300$ within the year 2024, \$400 in 2026, \$500 in 2027 and $\$ 600$ in 2031. (COIN PRICE FORECAST AGENCY, SEP. 6th, 2021)

Analyst suggestions: Apple price started in 2021 at \$132.69. Today (Sept 6th, 2021), Apple traded at $\$ 154.30$, so the price increased by $16 \%$ from the beginning of the year. The forecasted Apple price at the end of 2021 is $\$ 192$ - and the year-to-year change is $+45 \%$. The rise from today to year-end: $+24 \%$. In the first half of 2022, the Apple price will climb to $\$ 225$; in the second half, the price would add $\$ 2$ and close the year at $\$ 227$, which is $+47 \%$ to the current price.

\section{INTRODUCTION TO CHOOSER OPTION \& BLACK SCHOLES MODEL}

A chooser option in finance refers to a contract that offers the holder a chance to decide whether to take a put or call option. This is usually done ahead of the expiration date. Chooser options have a set expiration date and striker price regardless of the option the owner of the stock takes. In the case of a rising value of the underlying asset over a period of time, the holder of the option will choose the call option because it will have a higher value than the put option. When the underlying asset falls up, the choice will be the put option. Once this choice has been made at time $t$, the option stays as either a call or a put to maturity if the strike prices of the call and the put are the same, just as their expiration dates.

\subsection{Theoretical Aspects of Exotic Options}

\subsubsection{Categorization}

According to [5] Mark Rubinstein and Eric Reiner (1992), exotic options can be divided into eleven classes:

1) packages - options that are equivalent to a portfolio containing only standard European calls and possibly cash and the underlying asset itself.

2) forward-start options - options that are paid for in the present but which are only received at a prespecified future date.

3) compound options - options for whose underlying assets are themselves options.

4) chooser options - options that are paid for in the present but which at some

pre-specified future date is chosen to be either a put or a call.

5) barrier options - options whose payoff depends not only on the price at expiration of the underlying asset but also on whether or not the underlying asset has previously reached some other "barrier" price.

6) binary options - options with binary and discontinuous payoff patterns.

7) look-back options - options whose payoff depends not only on the price at expiration of the underlying asset but also on the minimum or maximum price experienced by the underlying asset during at least some portion of the option's life.

8) "Asian" options - options whose payoff depends not only possible on the price at expiration of the underlying asset but also on the average price experienced by the underlying asset during at least some portion of the life of the option. 
9) exchange options - options to exchange one asset for another, which can be exercised early.

10) currency translated options - options whose underlying asset or strike price is denominated in a foreign currency at a random or pre-specified exchange rate.

11) two-colour "rainbow" options - options on two risky assets which cannot be interpreted as if they were options on a single underlying asset.

A chooser option is part of the compound option family. A standard chooser option is purchased in the present but gives its holder the right to decide at some point in time, but before maturity, whether the option will finally be a put or a call as the figure shows [6] Rubinstein, Reiner; Hull. The strike prices of either the put or the call can be the same but need not necessarily be the same [7] De Weert)

The chooser option is similar to holding a straddle strategy consisting of put and call options sharing the same strike price. They are similar in that the option of not betting on the stock will be bullish or bearish [8] (Whaley; Laurence). But the chooser holder does not have to pay for both options entirely. He is flexible in deciding which option to buy later. A straddle holder must pay for both options immediately. For this reason, the chooser options are less expensive than straddles, according to [9] Rubinstein, Reiner; Avellaneda, Laurence

\subsection{Example of Chooser Option in the Capital Market (AAPL)}

Apple Inc. (AAPL) is updating its earnings release in one month. And, the trader wants to have an option to choose depending on the direction it will take. The trader then decides to buy a chooser option which will expire in three weeks after the release. So, this chooser option allows the trader to choose a call option if the pricing of the release rises or a put option if the prices fall. Note that, An American option may be exercised at any time prior to the expiration date. On the other hand, a European option may be exercised only at the expiration date. (CNBC STOCK 2021). One advantage of this type of option is that it can be applied in almost every market situation. However, it may require the trader to have a clearer vision to choose between the two options.

The time of making a choice also has to be put into consideration. The reason being is it also affects the price of a chooser option. It is a suitable choice for traders who anticipate strong volatility but they are unsure of the direction to purchase. Therefore, it became an appropriate mechanism as far as taking a volatility position is concerned. In other words, chooser options provide both shareholders and intended buyers with the flexibility to choose that will benefit them.

\subsection{Black-Scholes Model}

In this paper, we demonstrate how it can be applied to analyze chooser options. We price the options using various methods combined with the analytical BlackScholes model - the most popular option valuation model based on [10] Cuthbertson, Nitzsche. The model is based on the assumptions that markets are arbitragefree and the price of the underlying asset follows our expectations to finalize our solution, relating to the case of the European call/put options. BSM is a differential equation used to solve for options prices. The key financial insight behind the Black Scholes equation is that we can perfectly hedge the option by buying and selling the underlying asset and cash in just the right way and eliminate much of the unexpected risks. Using current stock prices, expected dividends, the option's strike price, expected interest rates, time to expiration, and expected volatility, the traders would easily be able to calculate the theoretical value of the stock.

\subsubsection{Historical background}

The initial equation of the Black-Scholes Model was introduced in Black and Scholes' 1973 paper, "The Pricing of Options and Corporate Liabilities," published in the Journal of Political Economy. It is one of the most important concepts in modern financial theory, developed in 1973 by Fischer Black, Robert Merton, and Myron Scholes and this model are still widely used today. It is regarded as one of the best ways of determining the fair price of options. Black passed away two years before Scholes and Merton were awarded the 1997 Nobel Prize in economics for their work in finding a new method to determine the value of derivatives. The Nobel Prize is not given. However, the Nobel committee acknowledged Black's role in the BlackScholes model. The mathematics involved in the formula is complicated and can be intimidating, but options traders don't need to necessarily understand the derivative itself to make rational decisions.

In 1997, Scholes and Merton were awarded the Nobel Memorial Prize in Economic Sciences for their work in finding "a new method to determine the value of derivatives." Unfortunately, black had passed away two years earlier and so could not be a recipient, as Nobel Prizes are not given posthumously; however, the Nobel committee acknowledged his role in the BlackScholes model. 


\subsection{Pricing}

\subsubsection{Understanding Simple Chooser pricing}

The main options pricing models contain five factors that are used to determine a theoretical value for an option, and which must be considered when pricing option contracts (Hull):

Simple choosers have the same strike price and time to maturity for the call and the put. Their price is defined by the following equations, derived by Rubinstein in the year 1991.

- market price of the underlying asset

- strike price

- time to expiration

- volatility of the underlying asset

- interest rates

- dividends expected during the life of the option

An analytical solution for pricing the chooser option is possible because of the options underlying the chooser are both European and have the same strike price. Therefore, put-call parity can be used to provide a valuation formula. This was proven by Rubinstein in 1991.

\subsubsection{Black-Scholes Model Simulation}

At time $t$ the investor will choose the higher value of the two options, that is, he will choose the call if (Cuthbertson, Nitzsche)

$$
C(S t, K, T-t)>P(S t, K, T-t)
$$

${ }^{1}$ According to the put-call parity

$$
(P+C=C+K e-r(T-t))
$$

then the equation reduces to:

$$
C>C+K e-r(T-t)-S
$$

And vice versa that the investor will choose Put when

$$
S t>K e-r(T-t)
$$

Table 7. The payoff from the chooser options at time T [11] (Cuthbertson, Nitzsche; Deacon et al.; Sandman, Wittke)

\begin{tabular}{lc}
\hline The choice at Time t & Payoff at T \\
Call & 0 \\
Put & 0 \\
\hline
\end{tabular}

At the time when the choice is made, the value of the chooser option is (Cuthbertson, Nitzsche; Rubinstein, Reiner)

$\mathrm{C}=$ the value of the call underlying asset

$\mathrm{P}=$ the value of the put underlying asset

Chooser simple $=\max [C(S t, K, T-t), P(S t, K, T-$ $t) ; t$

The first term evaluates the current value of a call option with underlying asset price $\mathrm{S}$, strike price $\mathrm{K}$ and time to maturity $\mathrm{T}-\mathrm{t}$, the second term is the value of a put with underlying asset price $\mathrm{Se}-\mathrm{q}(\mathrm{T}-\mathrm{t})$, strike price $\mathrm{Ke}$ $\mathrm{r}(\mathrm{T}-\mathrm{t})$ and time to expiration $\mathrm{T}-\mathrm{t}$, therefore, using BSM:

Chooser $=C(S t, K, T-t)+P($ Ste $-q(T-t), K e-$ $r(T-t), T-t)$

\subsubsection{BSM Application}

CALL: $S e-q(T-t) N(d 1)-X e-r(T-t) N(d 2)(7)$

PUT: $X e-r(T-t) N(-d 2)-S e-q(T-t) N(-d 1)$

$\mathrm{d} 1=(\ln (\mathrm{S} / \mathrm{X})+(\mathrm{r}-\mathrm{q}+\sigma 2 / 2)(\mathrm{T}-\mathrm{t})) /(\sigma \mathrm{T}-\mathrm{t})$

$\mathrm{d} 2=\mathrm{d} 1-\sigma \mathrm{T}$

$\mathrm{c}$ - the premium of the European call option

$\mathrm{p}$ - the premium of the European put option, $\mathrm{S}$ stock price

$\mathrm{X}$ - exercise price

$\mathrm{T}-\mathrm{t}$ - time to maturity

$\mathrm{r}$ - risk-free interest rate

$\mathrm{q}$ - dividends

$\sigma-$ volatility of the stock price

Analysis: Although the Black-Scholes model is derived for valuing European call and put options on a non-dividend-paying stock, this model can be extended to deal with European call and put options on dividendpaying stocks, American options or options with different underlying assets when [12] Hull; Martin; [13] Jarrow, Rudd; Laurence, [14] Avellaneda; Whaley mentioned. 


\subsection{Limitations}

\subsubsection{Chooser Option drawbacks}

Most Chooser Options happen to be slightly more expensive and riskier than a single call or put option. In a futures contract, a person is obligated to a set of rulesThe Bottom Line. In today's market, many financial instruments have been introduced. This has brought complications in the market, and investors have to face this dilemma every day. This complexity issue has many exotic options in the market, which people have continued to misunderstand. Current studies have mostly focused on developing other models for pricing options. They have also described more clearly how they can be used in the market.

\subsubsection{Limitations of BSM}

As stated previously, The Black-Scholes model is used to calculate a theoretical price of the option, which means ignoring dividends paid during the life of the option using the five key determinants of an option's price mentioned before: stock price, strike price, volatility, time to expiration and risk-free [15] Brenner, Subrahmanyam.

Moreover, the BSM is only valid based on European options and does not consider that American style deals could be exercised before the expiration date. On the other hand, the model assumes dividends and risk-free rates are constant. However, it might not always be the case.

\section{INTRODUCTION TO CHOOSER OPTION \& BLACK SCHOLES MODEL}

This study focuses on the pricing of the chooser option. We built a BSM model simulation on Microsoft office Excel and considered factors (risk-free rate, volatility, time to maturity, dividend rate, spot price, strike price, and choose a date) that will influence the final price of the chooser option.

Our study simulates the AAPL's chooser option. All the data were collected between Aug1st Aug6th, 2021's synchronized information.

Independent variables include risk-free rate from treasury.com, volatility from a similar AAPL's option, time to choose the date, time to maturity, apple's dividend from apple's annual report, and spot price \& strike price from Yahoo finance.

Then we plug in all the data that we retrieve into the BSM simulation model: $S_{T}=S_{0} e^{\left(a-\frac{1}{2} \sigma^{2}\right) T+z \sigma \sqrt{T}}$

Unlike other options, two dates exist in the chooser option. They are the time to choose the date and time to maturity. Thus, we have two sets of simulations, and each set simulates one thousand times. The first set of simulations simulates the pricing of the chooser option to the time to the chosen date. The second set of simulations simulates the pricing of the chooser option to the time to maturity. The call option price was determined by the largest number between the price of time to maturity - strike price and 0 . The put option price was determined by the largest number between the strike price - the price of time to maturity and 0 . We assumed that individuals would choose whether to be a call or put based on the chosen date price. If the price on choose date was higher than the strike price, the individual would choose to be a call. Otherwise, they would choose to be a put. In the end, the chooser option price was the highest number between call and put option price. We then take the average value of one thousand simulation times $e^{- \text {riskfreerate*timetomaturity }}$ to get the PV (present value) of the chooser option, which is 19.5 dollars. This value is more like a mean of one thousand simulations.

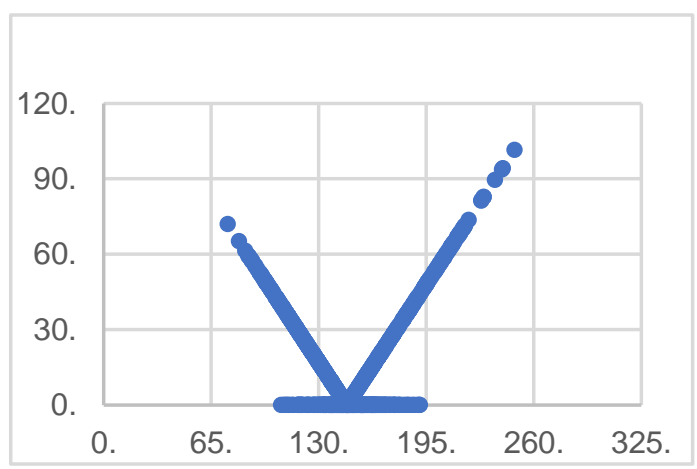

Figure 1. Chooser option price-scatter plot simulation

However, the value of one thousand simulations dotted plot on the left can demonstrate this evaluation more clearly. Those dots equal to zero represents that the market behaves the opposite way where investors predict.

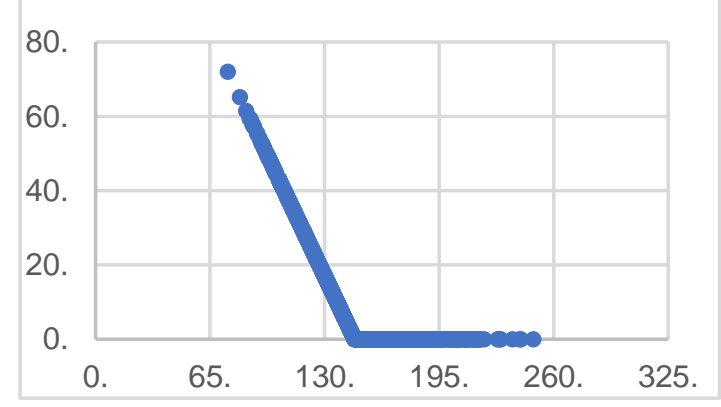

Figure 2. call option price scatters plot simulation 


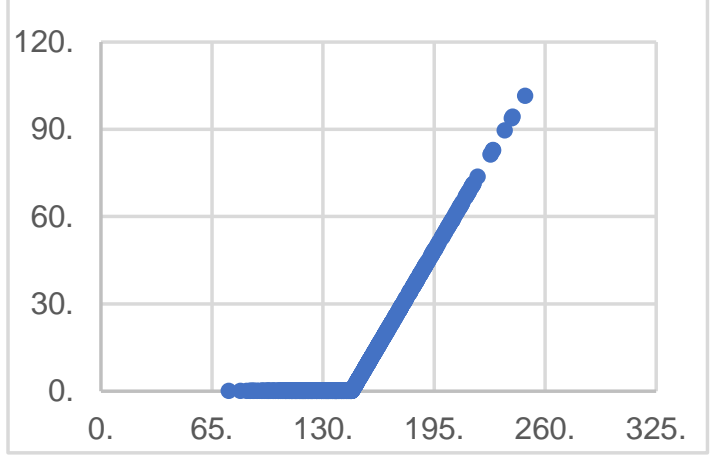

Figure 3. put option price scatters plot simulation

In contrast, those above zero represent profit, in other words, the price of the chooser option. We can see that the chooser option price is like a call option and put option from the graph. This has a similar concept with "straddle" (buy call and put option at the same time). The only difference is that the chooser option has a chosen date, which means you choose to either be a call or put. This reveals that the chooser option has a potentially higher profit. Since before the chosen date, investors do not care about whether the stock price goes up or down. As long as there are intense fluctuations, they can gain a decent amount of revenue. This also correlates with the result below that why volatility has such a high sensitivity.

\section{SENSITIVITY ANALYSIS}

In sensitivity analysis, we repeat the process of the pricing model and change those dependent variables one by one while others are fixed. We use what-if analysis in Excel. The variables that we simulate include stock price, time to maturity, volatility, and time to choose the date.

\section{1-market price}

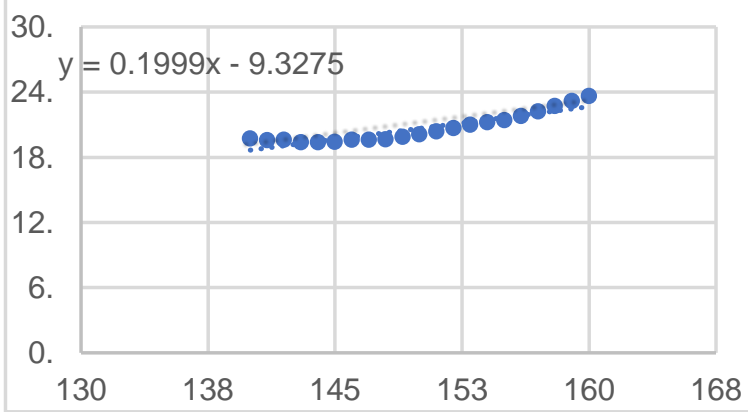

Figure4 call option price scatters plot simulation

We built a BSM model simulation on Microsoft office Excel and considered factors (risk-free rate,

\section{2-time maturity}

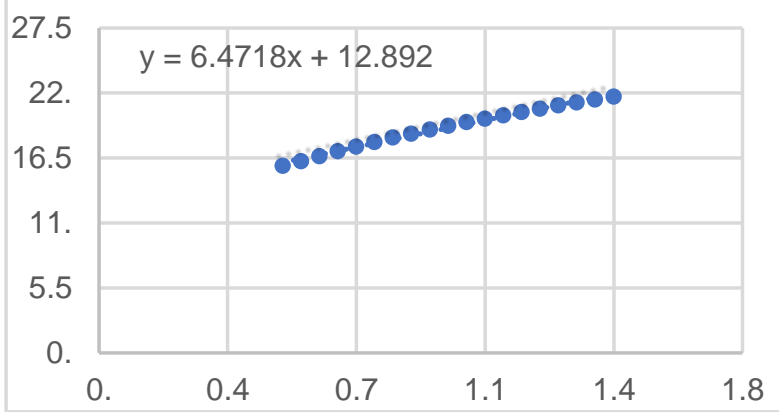

Figure5 Time to maturity sensitivity analysis

In the sensitivity analysis of time to maturity, the same processes were repeated as the last sensitivity analysis except that the independent variable switched to time to maturity from $0.5 \sim 1.4$ with a step of 0.05 . The per cent increase is $33.15 \%$.

\section{3-volatility}

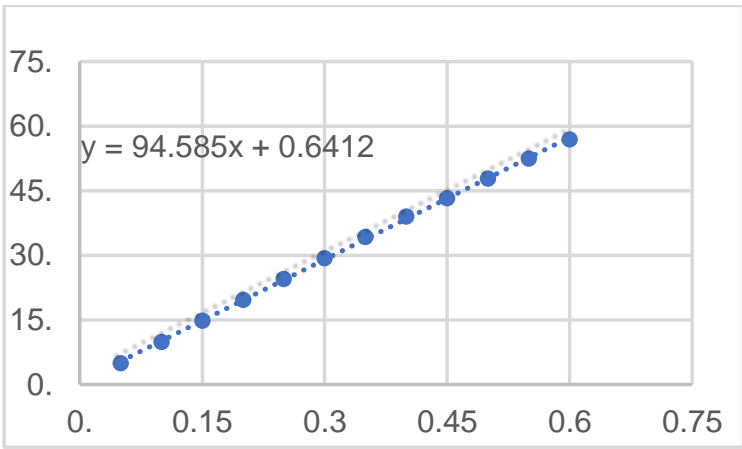

Figure6 volatility sensitivity analysis

The same processes were repeated as the last sensitivity analysis except that the independent variable change to volatility from $0.05 \sim 0.6$ with a step of 0.05 . The per cent increase is $484.46 \%$.

\section{4-time to choose the date}

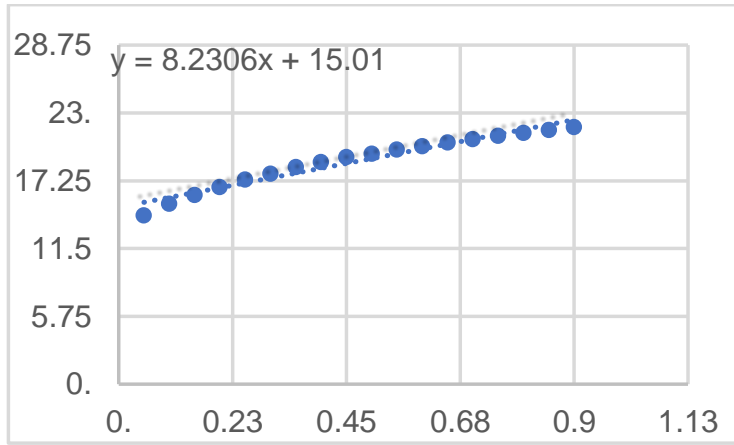

Figure7 Time to choose date sensitivity analysis 
The same processes were repeated as the last sensitivity analysis except that the independent variable changes the time to choose the date from 0.05 0.9 with a step of 0.05 . Again, the per cent increase is $42.16 \%$.

Based on the sensitivity analysis results, we can see that the factor that has the largest influence on chooser option price is volatility. This shows that fluctuation is what chooser option investors would favour the most. This is because the chooser option is similar to the combination of a call and a put option. This means that it does not matter whether the price goes up or down. As long as it fluctuates and investors figure out the right direction of market movement, they can gain a decent profit. Time to maturity and time to choose the date to have the second-highest sensitivity. This is because the longer the time range, the higher the chance the investor has a wrong prediction about the market.

\section{CONCLUSION}

This study uses the BSM model to model the chooser option price and sensitivity of different factors of the AAPL chooser option. The chooser option pricing simulation reveals unique characteristics of the chooser option. Those are more obvious in comparison with the call and put option. In the second part of our research, we conducted volatility analysis which reveals the factors that influence the chooser option price the most to least. This study can help investors get a sense of how different influential factors are a specific case study of AAPL's chooser option.

By using the BSM model, we determined the chooser option price and the sensitivity of different factors. The first part of our research is determined the price of AAPL's chooser option, which is approximately 19.5 dollars. Compared to the call option with an approximately 11.5 dollars price and put option with an approximately 11.8 dollars price, the chooser option has about 8 dollars higher than them. Since this data is not determined by a single case but one thousand tines of simulations, we conclude that the chooser option has a relatively higher potential profit than both calls and put options. In the second part of our research, we found out the sensitivity of different factors: volatility $484.46 \%$, time to choose date $42.16 \%$, time to maturity $33.15 \%$, and market price $1.02 \%$. This reveals the intensity of influence to the chooser option price from the change of each factor. And in this case, volatility is the most influential factor due to the way how chooser options work.

There are several limitations of our research, though. Firstly, our logic of choosing whether to be a call or put on choose date is based on the exact value at that time. This means that if the choose date price is higher than the stock price, we assume the investor chooses the call option. Similarly, if the choose date price is lower than the stock price, then we assume the investor chose the put option. However, some investors would make decisions based on the trend of price fluctuations or the company's reputation. This is the part we cannot figure out how to simulate at the moment. Secondly, the independent variables in the volatility analysis are assumed by us based on a vague estimation of how the market will behave. There are no precise calculations involved which can be improved in future studies.

\section{REFERENCES}

[1] Rubinstein, M.; Reiner, E. 1992. Exotic options. Working Paper 220. Available from Internet: http://www.haas.berkeley.edu/groups/finance/WP/r pf220.pdf.

[2] Sandmann, K.; Wittke, M. 2010. It's your choice: a unified approach to chooser options, International Journal of Theoretical \& Applied Finance13(1):139-161. http://dx.doi.org/10.1142/S0219024910005711

[3] Brenner, M.; Subrahmanyam, M. G. 1994. A simple approach to option valuation and hedging in the Black-Scholes model, Financial Analysis Journal 50(2): 25-28. http://dx.doi.org/10.2469/faj.v50.n2.25

[4] 2012. Exotic options:a chooser option and its pricing, Business, Management and Education10(2):289-301. http://dx.doi.org/10.3846/bme.2012.20

[5] Zhang, P. G. 1995. An introduction to exotic options, European Financial Management 1(1): 8796.

http://dx.doi.org/10.1111/j.1468036X.1995.tb0000 8.x

[6] Apple Inc. (NASDAQ:AAPL). (n.d.). Stock Analysis on Net. https://www.stock-analysis- [8]H. Barringer, R. Kuiper, A. Pnueli, Now you may compose temporal logic specifications, in: Proceedings of the Sixteenth Annual ACM Symposium on the Theory of Computing (STOC), ACM, 1984, pp. 51-63. DOI: https://doi.org/10.1145/800057.808665

[7] Weert, De F. 2008. Exotic options trading. John Wiley \& Sons. eBook. 205p. Available from Internet: eBook Academic Collection < http://web.ebscohost.com>.

[8] Bampou, D. 2008. Numerical methods for pricing exotic options: Master thesis. Available from Internet:

http://www3.imperial.ac.uk/pls/portallive/docs/1/4 5415707.PDF 
[9] Krawiec, K. D. 1998. More than just "new financial bingo": A risk-based approach to understanding derivatives, Journal of Corporation Law 23: 1-63.

[10] Apple Inc. Common stock (AAPL) dividend history. (n.d.). https://www.nasdaq.com/marketactivity/stocks/aapl/dividend-history

[11] Predota, M. 2005. On European and Asian option pricing in the generalized hyperbolic model, European Journal of Applied Mathematics 16(01): 111-144 http://dx.doi:10.1017/S095679250400542X.

[12] Krawiec, K. D. 1998. More than just "new financial bingo": A risk-based approach to understanding derivatives, Journal of Corporation Law 23: 1-63.

[13] Buchen, P. W. 2004. The pricing of dual-expiry exotics, Quantitative Finance 4(1): 101108.http://dx.doi.org/10.1088/1469-7688/4/1/009 